\title{
NRC Reviews Surface Processing of Electronic Materials in the United States and Japan
}

\author{
NMAB Panel on Materials Science Identifies \\ U.S. Strengths, Weaknesses, Recommends New Strategies
}

The main message of a 42-page National Research Council (NRC) report on Advanced Processing of Electronic Materials in the United States and Japan is that the Japanese have entered a state of accelerated development in electronic materials processing and that the overall position of the United States in electronics has worsened acutely in the last few years.

Market analysts have projected worldwide sales exceeding $\$ 50$ billion by 1990 for semiconductor device production alone. From 1980 to 1985, however, the U.S. share of this world market dropped substantially-from 64 to $53 \%$. "During the past 30 years the importance of electronic materials to U.S. science and commerce has become immense," so that "a loss of leadership in this area will have significant consequences," concludes the report. It is in the increasingly important area of surface processing - the focus of the panel's investigation-that the United States is losing the leadership to Japan.

The report's most important implication, though, is that traditional American $R \& D$ strategy (where industrial laboratories concentrate on short-term product development, government laboratories confine themselves to mission-oriented projects, and universities examine phenomena that may have no immediate use) is no longer appropriate for semiconductors.

\section{U.S. Strengths}

The report concludes that the United States still has the technological edge in three areas-ion implantation, thin film epitaxy (chemical vapor deposition, molecular beam epitaxy, and metallo-organic chemical vapor deposition), and film deposition and etching. "However," the report warns, "the Japanese have mounted strong programs in all three areas, and this balance could easily shift in the next few years." Within the past year the United States has slipped behind in optical lithography.

The panel identifies one area where the United States has significant strength, and that is in its university programs. At least six universities in the United States have strong academic programs in electronic materials, academic programs backed by equally strong research programs pertinent to industry's needs. "The U.S. university system produces graduates who are familiar with equipment and procedures in the semiconductor industry and are qualified to take on responsible $R \& D$ positions in the industry." Only about half as many Japanese universities are similarly involved.
Japanese universities graduate more engineers per capita than U.S. universities, but their programs are more academic, with less emphasis on laboratory training and advanced research. "It is U.S. companies and government laboratories that appear to be lagging behind their Japanese counterparts," says the report.

At present, the Japanese are ahead of the United States in the development and application of advanced processing technologies, especially because of a commitment to long-term R\&D by Japanese industry and because of the focus of government funding toward commercially viable areas. While 10 major semiconductor companies in Japan have vigorous programs for projects with an expected payoff $7-10$ years later, only a few U.S. firms have such longterm programs. The report cites government-funded research as a "potent catalyst" for long-range R\&D in Japan's industries. It also cites the Ministry of International Trade and Industry's (MITI's) focus of government funding into areas that are considered commercially viable in 5-10 years, noting that "the majority of U.S. government funding for electronics research is directed toward national defense and aerospace programs."

The report recommends "mechanisms to encourage long-term commitment to $R \& D$ in U.S. industry" and recognizes that U.S. government laboratories have the potential to provide substantial support to U.S companies, even though this "would require a change in emphasis from current policy."

"The area of most need appears to be intermediate between the truly long-range research and short-term processing R\&D necessary for present device technology," cites the panel. It recommendation is that U.S. industry be intimately involved with government laboratories. "This would allow the combined resources of government and industry to be directed toward relevant problems and to solve these problems on a set schedule in mesh with industry needs."

\section{Japanese Lead in Seven Emerging Technologies}

The panel identified seven emerging technological areas of key importance to continued

\section{FIBI-MBE CRYSTAL GROWTH SYSTEM}

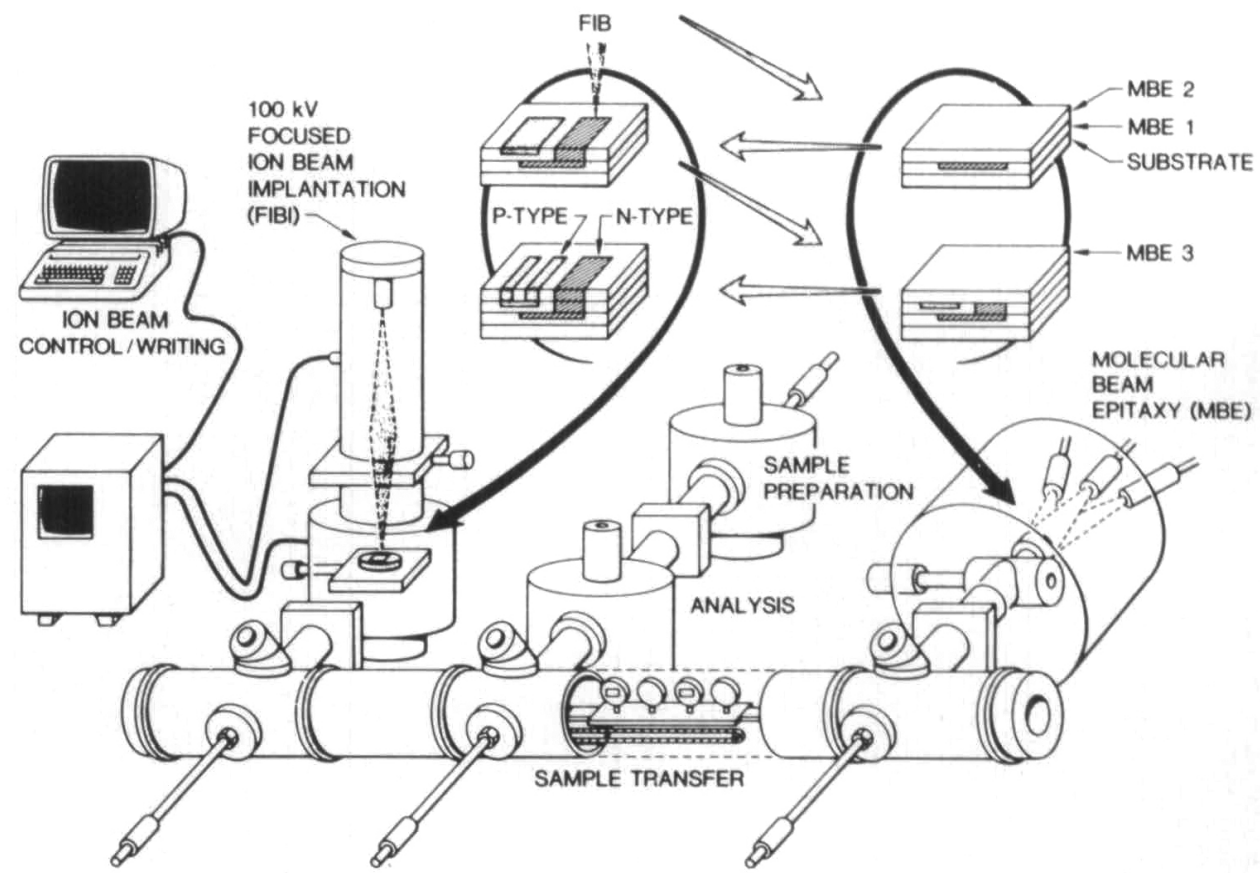

Optoelectronic device fabrication system integrates a focused ion beam implantation (FIBI) system, an MBE chamber, and sample preparation and analysis chambers into a common UHV processing system. Modified from an original drawing supplied by Optoelectronics Joint Research Laboratory. 
future electronic and optical device development, areas where U.S. R\&D is lagging behind Japan's: microwave plasma processing, lithographic sources, electron and ion microbeams, laser-assisted processing, compound semiconductor processing, optoelectronic integrated circuits, and threedimensional device structures.

- Microwave Plasma Processing. The Japanese have developed microwave plasma systems with significant advantages over radio-frequency techniques. These microwave systems provide low-temperature, damage-free etching and deposition, characteristics considered crucial for future devices. "This technology is sufficiently developed so that implementation is imminent."

- Lithography Sources. Advances in the lithographic process require the development of higher resolution, and several Japanese companies are developing $x$-ray lithographic sources in the form of compact synchrotron radiation sources compatible with device processing.

- Electron and Ion Microbeams. Japan now leads in the development and use of this emerging technology and is the leading supplier of focused ion beam systems.

- Laser-Assisted Processing. Researchers in the United States and Japan are exploring a wide range of applications of lasers and incoherent light sources for low-temperature processing. Although this field is still in the exploratory stage, the potential for new discoveries and improved low-temperature CVD techniques is great.

- Compound Semiconductor Processing. Japanese labora tories seem to bet ter understand the entire spectrum of processing steps for GaAs (a potential replacement for silicon in some applications), from material growth to self-aligned gate implantations.

- Optoelectronic Integrated Circuits. One particularly innovative Japanese approach is the integration of sequential processing steps into one UHV processing system to fabricate complete structures. (See Figure.)

- Three-Dimensional Circuits. Stacking silicon active layers to achieve novel device configurations is being accomplished in Japan using scanned laser or electron beam sources to recrystallize silicon films on insulating layers.

\section{Key Ingredients for Japanese Success}

The report cites four key ingredients for the Japanese success in developing new electronic materials processing technologiescommitment, coupling, commerce, and creativity.

Japanese industry has made a long-term commitment to the development of new processing technologies and their application to new semiconductor structures. This commitment to long-range $R \& D$ involves not only university and government consortia, such as MITI, but also the major semiconductor industrial laboratories. MITI has designated several microelectronics projects requiring 10 or more years of $R \& D$ before they become marketable-superlattice devices, three-dimensional integrated circuits, hardened integrated circuits for extreme conditions, and, most recently, an eight-year project to develop advanced fabrication technologies and equipment for submicrometer-scale processing.

Coupling, or interaction and collaboration, is "remarkably efficient," according to the report. There is close interaction between exploratory $R \& D$ and device fabrication on one level, and between the equipment manufacturers and the semiconductor circuit manufacturers on another level.

As for commerce, Japan's semiconductor industry is made up of at least 10 firms that pursue long-range $R \& D$ on a scale matched by few U.S. companies. Besides deriving strength from this arrangement, each company covers the spectrum of product development from the lab to the marketplace. The commercial rivalry, "both domestic and international, between these giants fosters innovative research and development, leads to new products, and forces increased efficiency."

And contrary to widely held opinion, the Japanese are demonstrating considerable creativity and innovation in their $R \& D$ programs.

This NRC review, part of a group of state-of-the-art reviews initiated in 1985, was conducted by an eight-member Panel on Materials Science under the auspices of the National Materials Advisory Board (NMAB). To carry out this assessment, five of the panel members visited several prominent Japanese industrial and university laboratories, including the Optoelectronics Joint Research Laboratory sponsored by MITI.

The report was officially released on June 4 during a one-day seminar co-chaired by Frank Press, President of the National Academy of Sciences, and Robert White, President of the National Academy of Engineering. The five presentations summarizing the report included an introduction by Walter Bauer, the panel chairman, and talks on the U.S. and Japanese positions in key technology areas. Panel members making presentations were: $\mathrm{S}$. Tom Picraux (Sandia National Laboratories), Bill R Appleton (ORNL), Peter H. Rose (Eaton Corp.), and John M. Poate (AT\&T Bell Laboratories). About 130 policy makers from government, industry, and universities attended the seminar and debated the implications of the report.

Copies of Adranced Processing of Electronic Materinls in the United States and Japan are available from the National Materials Advisory Board, 2101 Constitution Avenue NW, Washington, DC 20478.

\title{
Membership in the Materials Research Society
}

The Materials Research Society is dedicated to fostering the exchange of scientific information across the many disciplines involved in materials research. Membership benefits include:

\author{
Subscription to Journal of Materials Research * \\ Subscription to MRS BULLETIN \\ Discounts on MRS proceedings \\ Discounts on special books published by other leading scientific publishers \\ Discount subscription to Materials Letters \\ Information on upcoming MRS meetings and short courses \\ Copy of the MRS Membership Directory \\ Discount subscriptions on journals published by the American \\ Institute of Physics \\ *Regular members only. Student members may subscribe for $\$ 15$
}

To join, contact the Materials Research Society, 9800 McKnight Road, Suite 327, Pittsburgh, PA 15237; telephone (412) 367-3003. 


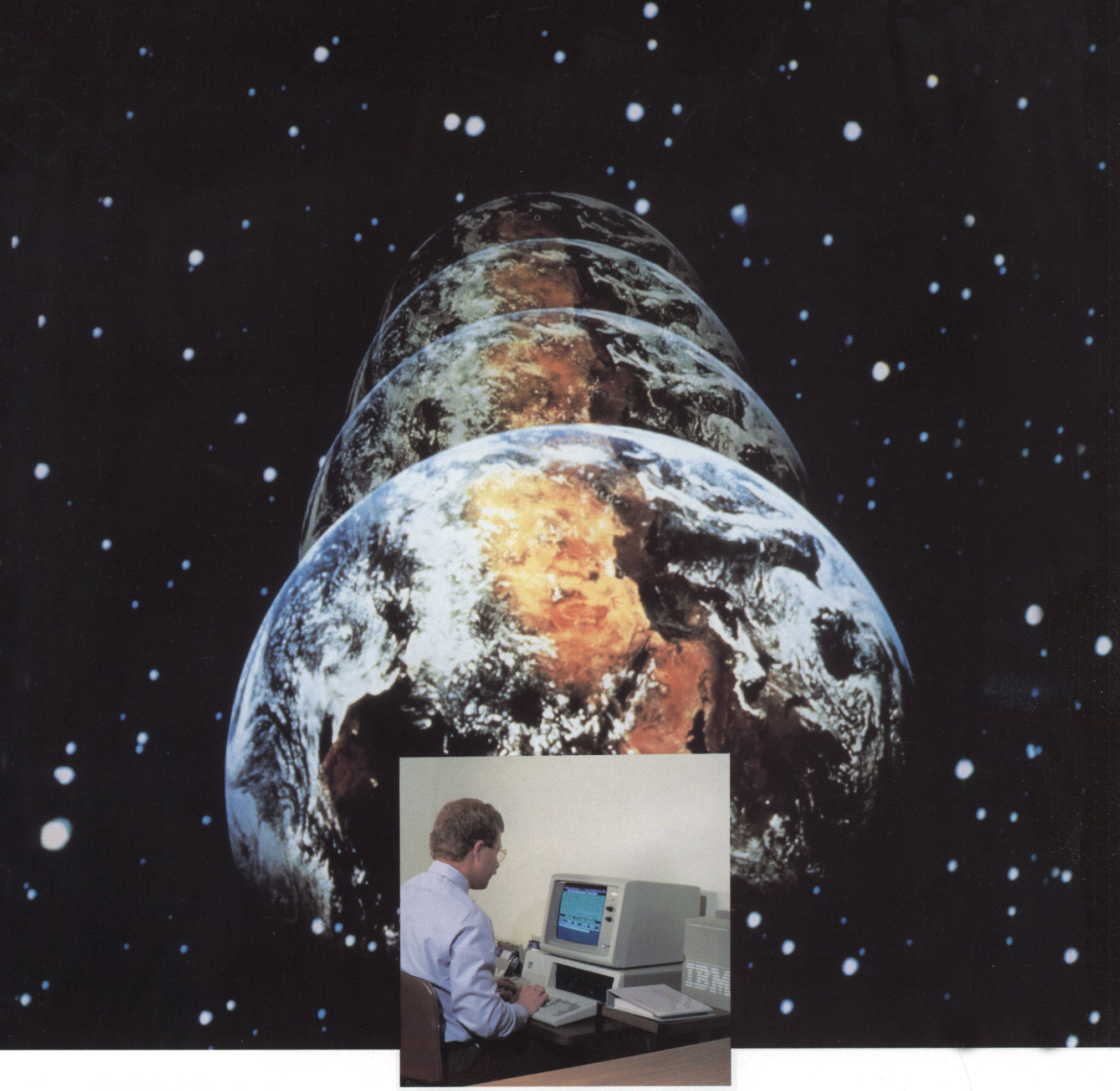

\section{$\mu$ PDSM puts the world of XRD analysis at your finger tips.}

Fein-Marquart has taken search/match out of the lab and literally put it at your finger tips with $\mu$ PDSMa full featured software program that gives you mainframe power for your IBM PC. Offering costeffective stand-alone use, $\mu$ PDSM allows you to analyze data from your diffractometer on your IBM PC. It delivers more accurate identification faster than any known alternative and gives you the 46,000 - pattern JCPDS library plus the capability of developing your own library. Whether your $\mathrm{x}$-ray diffractometer is manual, semiautomatic, or fully computer controlled, the $\mu$ PDSM is the answer to your direct interaction in solving simple or complex diffraction patterns. For information or a presentation on $\mu$ PDSM, call or write FMA.

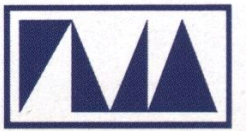

Fein-Marquart Associates, Inc. 7215 York Road

Baltimore, MD 21212

(301) 821-5980 